\title{
As incertezas de um pós-pandêmico: ainda resta oportunidade para uma "saída" virtuosa ao Brasil?
}

\author{
The uncertainties of a post-pandemic: is there still an \\ opportunity for a virtuous "exit" to Brazil?
}

Las incertidumbres de una pospandémica: ¿existe todavía una oportunidad para uma

"salida" virtuosa a Brasil?

\section{Organizadores}

\section{Léo Peixoto Rodrigues}

Licenciatura em Ciências Físicas e Biológicas pela Faculdade Porto Alegrense de Ciências e Letras (FAPA-RS); Pós-doutorado em Sociologia (UnB); Doutor em Sociologia (UFRGS); Prof. Associado do Instituto de Filosofia, Sociologia e Ciência Política e dos programas de Pós-Graduação em Sociologia e em Ciência Política da UFPel. E-mail: leo.peixotto@gmail.com

\section{Marcos Lacerda}

Pós-doutorando em sociologia pelo PPGS/UFPel. Núcleo de Interseccionalidades/PPGS/UFPel. Bolsista CA-PES. E-mail: lacerda.marcos81@gmail.com

\section{Aline Lamas}

Doutoranda do Programa de Pós-Graduação em Sociologia da Universidade Federal de Pelotas (UFPel). E-mail: alinelamas.ufpel@gmail.com 
Nesta introdução, cujo objetivo central é o de apresentar e falar um pouco sobre as valiosas contribuições de artigos inéditos de pesquisadores brasileiros e de outros países, gostaríamos também de fazer um breve antelóquio sobre este segundo número Especial da revista "Simbiótica" que continuará tratando da Pandemia da Covid-19, a exemplo do primeiro número. No início de 2019 aceitamos o gentil convite dos editores de "Simbiótica" para organizarmos um número especial que tratasse da pandemia causada pelo vírus Sars-Cov-2, a partir de uma perspectiva das ciências sociais. À época a Covid-19 recém chegara ao Brasil, mas os cuidados como distanciamento social e uso de máscaras já era corrente, sobretudo depois que a OMS, em 11 de março de 2019 - um tanto tardiamente -, recomendou internacionalmente o uso de tal assessório, às pessoas em geral, como prática protetiva.

À ocasião, verificava-se um certo silêncio das ciências sociais - tanto no âmbito do governo, como nas universidades e nas associações de classe - no que tange à construção de uma agenda, sobretudo científica, sobre como lidar com a pandemia, em diferentes níveis da sociedade. A pandemia parecia ser um problema exclusivamente sanitário e deveria ficar afeto às ciências biomédicas, como de fato, majoritariamente, acabou ficando. Aceitamos o desafio e a Simbiótica, como uma revista de ciências sociais, vinculada ao PPGCS da Universidade do Espirito Santo, teve seu pioneirismo não apenas assegurado como também reconhecido, tendo recebido um considerável número de citações em diferentes países, inclusive na própria China, onde, devemos lembrar, tudo começou. Se por um lado nos orgulhamos por aceitar o desafio de "Simbiótica", por outro lado lastimamos que tenha sido para abordar e discutir um tema tão catastrófico, com tanta dor e vidas ceivadas.

Passado um ano desde o primeiro número Especial, cuja repercussão ajudou a sociologia, como ciência, a assumir um maior protagonismo sobre o tema junto no âmbito acadêmico (desde então já foram vários os dossiês científicos publicados sobre a Pandemia) -, fomos desafiados novamente à organizar um novo número especial - referimo-nos, no plural, enquanto pesquisadores-organizadores da UFPel-RS, universidade esta que tem apresentado um papel de destaque, interdisciplinar, desde o início da pandemia. Desde então, muito mudou e novos enfoques (e desafios) sobre a pandemia emergiram como poderá ser visto neste segundo número Especial.

Nosso artigo introdutório ao dossiê organizado há um ano atrás (Rodrigues; Costa; Guedes, 2020) revelava, por um lado, toda a nossa prudência em abordar o tema da pandemia; dizíamos: "As ciências sociais são mais cautelosas e geralmente recomendam que tomemos o necessário e prudente distanciamento temporal dos fatos. Entretanto, as mesmas boas razões que apontam para a prudência, também apontam para a necessidade de imediatas reflexões sociais” 
(Rodrigues; Costa; Guedes, 2020:2). Por outro lado, éramos desejosos de otimismo e o título do Dossiê anterior refletia isto; estampava ele: "Em tempos de pandemia: para um pósepidêmico como oportunidade virtuosa". A maioria de nós acreditava que a pandemia não avançaria por mais de um semestre, um ano e, com as medidas que estavam sendo providenciadas, parecia ser possível sairmos fortalecidos de tal adversidade. Entretanto, o "póspandemia" foi ficando (e ainda está) cada vez mais distante - mesmo tendo se passado quase 18 meses desde que a infecção teve início no Brasil. Ainda estamos - não obstante ao fato de que mais da metade dos brasileiros estejam vacinados com a primeira dose da vacina - em meio à propagação do Corona vírus, e com uma contabilidade de quase 600 milhões de pessoas mortas em nosso país e milhares de brasileiros enlutados. Os espaços para otimismo foram, como as vidas, drasticamente sendo aos poucos ceivado.

Já se fala menos de um pós-pandemia, como se falava há um ano. Pelo menos não se fala mais em um "pós" como uma ruptura total com a pandemia, como se o vírus fosse desaparecer por completo. Estávamos corretos quando mencionamos anteriormente que o debate sobre um mundo "pós-pandemia talvez fosse um efeito colateral do isolamento, das restrições ou da quebra, mesmo que mínima, da normalidade [fazendo com que] a sociedade se refugiasse na projeção do futuro; na promessa a si mesma de um 'eu vou fazer/ser diferente"” (Rodrigues; Costa; Guedes, 2020:3).

À ocasião da reflexão introdutória do número Especial anterior de "Simbiótica" advertimos - para alguns um tanto premonitoriamente:

Certamente o Brasil pode, considerando o seu sistema social e seus múltiplos
subsistemas, fazer duas opções - como no filme The Matrix (1999) -, ou seja, escolher
entre dois caminhos que se afiguram excludentes entre si: a) olhar para todos os
equívocos cometidos no decorrer da pandemia que, de certo modo, nos conferiu a
possibilidade de observação privilegiada, e alterar construtivamente o seu curso de
certos acontecimentos; b) não considerar (ou não perceber) os equívocos cometidos
durante a pandemia, tampouco a possibilidade de observação privilegiada, e
permanecer, não-construtivamente no seu curso (Rodrigues; Costa; Guedes, 2020:4).

Passado o lapso temporal de um ano, constatamos que no caso brasileiro os caminhos escolhidos foram aqueles mais tortuosos, ou seja, caminhos nos quais a virtuosidade das ações, que deveria ser voltada à soberania (ou supremacia?) do povo, foi eclipsada por imbróglios políticos, cuja finalidade foi (e continua sendo) uma disputa, não por uma agenda dignificante da condição de vida dos brasileiros, mas pelo poder (ou nacos dele) a punhados de elites políticas.

Então, consideramos, reflexionamos sobre os rumos internacionais e aqueles nacionais equivocados que estavam sendo tomados à época, com relação à pandemia? Parece que não! Parece que como sociedade escolhemos mais aquilo que tem representado a "pílula vermelha" que propriamente aquilo que tem representado a "pílula verde", socorrendo-nos mais uma vez da 
metáfora de Matrix (1999). De fato não são muitos os caminhos virtuosos que tomamos e que possamos nos orgulhar, cremos. Em junho de 2019, projetávamos (e indicávamos) a possibilidade de algumas saídas virtuosas de um "pós-pandemia" aos diferentes sistemas sociais; hoje, decorrido ano e poucos meses, retornamos nesta segunda Edição especial com menos expectativas e mais questionamentos, indagações que se fazem necessárias a todos: poder público e sociedade civil.

Quais foram os ganhos efetivos até então ao nosso sistema de saúde; já é possível quantificá-los? A efetiva injeção de recursos financeiros que os estados federados deveriam e devem aplicar foram de fato aplicados como deveriam ter sido? Houve desvios? Serão apurados ou não? Tem havido efetividade mensuráveis no âmbito da saúde independentemente "dentro" e "fora” da pandemia? O Sistema Único de Saúde (SUS), patrimônio do povo brasileiro e não de governos transitórios (municipal, estadual ou federal) tem se tornado mais eficiente posto que outras enfermidades destes quase dois anos não pararam de ocorre?

O sistema educacional igualmente já está quantificando os indiscutíveis prejuízos materiais, mas principalmente imateriais ou cognitivos, com a supressão da maioria das aulas presenciais? Já está havendo por parte dos gestores, em diferentes níveis da federação, uma bem adequada preparação para um retorno presencial eficiente e seguro à saúde das pessoas, ou nos restará lastimar (novamente) aquilo que não consideramos, supomos ou planejamos? Que balanço que está sendo feito - se está - sobre esse "laboratório forçado", ao qual todo o ensino brasileiro foi submetido, no que concerne à eficácia do ensino à distância. Quem sabe uma ampla e competente pesquisa devesse ser feita junto à comunidade estudantil nacional, em seus diferentes níveis, ouvindo principalmente professores, alunos e gestores? Vamos quantificar os prejuízos, ou agir como se eles de fato não tivessem ocorridos?

Considerando o sistema social, as pessoas como um todo, o "homem comum" ou ainda o "povo" - aqueles para quem tudo o mais faz sentido e tem a sua razão de ser e de existir, inclusive o Estado, pelo menos nas democracias - como de fato está vivendo (sobrevivendo?) para além de disputas políticas paroquiais a essa altura desta trágica pandemia? Que centralidade de fato as pessoas estão tendo em meio a uma certa "bolha" de disputas nada republicanas e de acirramento das tenções com vistas exclusiva ao poder?

Orientados pelo otimismo que guardávamos há mais de um ano e que de certo modo soçobrou, buscamos resgatá-lo - no ato virtuoso de negar energicamente o pessimismo -, renovando uma série de questionamentos relacionados a algum dos mais importantes sistemas da sociedade. Assim, o título que propomos a esta segunda oportunidade de tratar da pandemia neste Dossiê é: As incertezas de um Pós-pandêmico: ainda resta oportunidade para uma 
"saída" virtuosa ao Brasil? Certamente que as contribuições aqui apresentadas em forma de entrevista e de artigos, fruto de investigações e/ou áreas de reflexões e de expertises dos/as pesquisadores/as colaboradores/as deste número - aos quais somos muito gratos -, buscam problematizar boa parte dos questionamento aqui levantados.

Esta edição Especial é aberta com a corajosa, lúcida e técnica Entrevista concedida por Pedro Curi Hallal, ex-reitor da UFPel-RS, epidemiologista, e que tem tido uma destacada atuação nacional e internacional particularmente durante neste período de pandemia da Covide19. A entrevista, conduzida por Aline Lamas, organizadora deste Dossiê, é clara, direta, aberta que toca em pontos cruciais sobre como a infecção pandêmica pelos Sars-Cov-2 desenvolveu-se no Brasil, considerando as implicações diretas e indiretas com o governo brasileiro. Além disto, na entrevista, Hallal mostra uma marcada preocupação social, com as pessoas, com o "povo" neste momento tão delicado do nosso País.

O artigo de Ivan da Gosta Marques, intitulado Ciência e negacionismos: pelo menos um $\boldsymbol{X}$ das questões a partir da perspectiva dos "estudos sociais da ciência e das tecnologias", problematizará o fato de que se por um lado os ESC\&T possibilitaram novas formas de convívio pacífico com "modos de vida" estranhos às ciências, por outro lado, oportunizaram a construção de abordagens "negacionistas" da própria ciência. A partir de então, Marques vai destacar que o abandono a ideia de que os conhecimentos científicos necessitam, obrigatoriamente, ser universais, neutros e objetivos tem visado o fortalecimento e não o enfraquecimento dos conhecimentos científicos, através de salutares debates acerva das controvérsias. Destaca, entretanto, que a partir de então tem vindo à tona “execráveis 'mercadores da dúvida' que, com recursos, apostam da desqualificação dos conhecimentos científicos e dos cientistas". A partir daí, Marques vai construir seu argumento considerando o seguinte questionamento: "Como tratar o fim da ilusão absolutista da Ciência e não jogar fora os conhecimentos científicos?”.

Marcos Lacerda, Léo Peixoto Rodrigues e Everton Garcia da Costa no artigo Ciência, pandemia e lockdown: o lugar vago da Sociologia partem e assumem como um fato indubitável que "no âmbito do conhecimento científico médico e, mais amplamente, biomédico, tanto o distanciamento social, como o lockdown são eficazes contra a propagação do Sars-Cov-2". Entretanto, os autores propões que se traga ao lado dessa premissa assumida como verdadeira - é importante que se frise - há uma tensão entre consenso biomédico e racionalização da conduta social, dada a existência de condições sociais concretas que impedem essa plena realização da racionalização. A partir daí, Lacerda, Rodrigues e Costa desenvolvem o argumento central do artigo, onde buscam demonstrar a natureza irremediavelmente gregária do social, ao tempo em que os autores questionam o lugar da sociologia, como ciência - criticando seu excedente de 
"ativismo militante" -, para, ao lado das ciências biomédicas, e em condições de plena igualdade, encontrarem possibilidades conjuntas com relação às medidas restritivas, tornando-as mais eficientes quanto à mitigação dos efeitos da pandemia.

Ao observarem os processos de aceleração e desaceleração do tempo social impostos pela pandemia Covid-19 nas diferentes dimensões do sistema da sociedade Laura Storch e Eduardo Rosa Guedes, em Reflexos sociotemporais da pandemia de Covid-19 no Jornalismo: processos de aceleração e desaceleração do Tempo Social propõem-se a problematizar essa questão no campo do jornalismo. Ao apresentarem e discutirem a noção de tempo social, proposta pelo sociólogo alemão Hartmut Rosa, os autores debruçam-se sobre os reflexos acelerativos e desacelerativos da pandemia nas rotinas e práticas sociais vinculados à produção e circulação de conteúdos jornalísticos. Ao considerarem o que Rosa tem chamado de "aceleração técnica" - um processo intencional promovido pelos desenvolvimentos tecnológicos "direcionados a um objetivo", Storch e Guedes, reconhecem, no contexto da Comunicação, um aumento da demanda por conteúdo online.

No próximo artigo, A crise da Covid-19 e o sistema mundo: perspectivas sobre epidemias na história e desigualdades globais, Rodrigo Cantu apresenta um quadro histórico amplo, com uma análise que abrange uma história longa sobre pandemias, para além da nossa atual, embora mantendo a pandemia da COVID-19 como foco central. Esta gênese se dá, especialmente, na seção do artigo "As epidemias na dinâmica social de longa duração", com um trabalho cuidadoso de apresentação de exemplos de surtos pandêmico, num recuo histórico e arqueológico de grande valor. A base da sua análise é a teoria do sistema mundo. Vale a leitura atenta também do primeiro tópico, que apresenta as diferentes formas de disseminação da pandemia em diversos contextos regionais no mundo, em especial nas periferias do capitalismo global, após um ano de pandemia. Trabalho engenhoso que culmina, nos comentários finais, com a extensão da análise para as sociedades capitalistas do século XXI, com ênfase no jogo entre as potências dos EUA e China, as semiperiferias, e as periferias do sistema mundo. E que se divide, ainda mais, em três perspectivas: a pandemia deve ser entendida como um fator endógeno ao sistema mundo capitalista; as desigualdades sociais no âmbito do sistema mundo devem ser levadas em consideração como foco da análise e, por fim, há algo como uma disputa por hegemonia no que diz respeito ao controle dos processos de tratamento médico da pandemia entre as potências mundiais.

Já Caio Souto, no texto que segue o Dossiê, Reflexões sobre a crise, faz uma gênese do conceito de crise para pensar a atual crise mundial da Covid-19, passando por um amplo leque de possibilidades de significados na história do pensamento: crise no âmbito da Grécia antiga; no 
direito e teologia; no que o autor chama de "história europeia", a partir de meados do século XVII, quando o termo passa a se referir mais propriamente a processos sociais e históricos, para no século XVIII se confundir com a própria Modernidade, como se houvesse uma relação de analogia, ou para usar um termo weberiano, uma conexão de sentido entre crise e modernidade. Crise, modernidade e crítica, pois há uma relação possível entre a consciência da crise e a possibilidade de superá-la através da crítica. $\mathrm{O}$ artigo faz, com elegância estilística e senso de medida, um longo percurso pelas tramas das formas de racionalidade moderna, da historicidade de conceitos como os de "vida", dos campos de luta que envolvem a própria conceituação para "além" da própria racionalidade moderna. Sugere possíveis caminhos de saída da crise com a atuação decisiva de novos atores sociais, especialmente no contexto pandêmico e como reação à aparição e consolidação no poder da "nova direita", e vincula, de forma sutil e inventiva, todos estes temas com a própria história política recente do Brasil.

A partir de aportes teóricos da abordagem sistêmica de Niklas Luhmann, Julio Roberto Labraña Vargas, María Antonieta Urquieta Álvarez e Sofia Adela Salinas Fuentealba em Espaço e educação: desafios da educação a distância no contexto da pandemia COVID 19 abordam a educação on line, considerando o atual momento da pandemia, que alterou significativamente o funcionamento das instituições educacionais, devido a adoção de estratégias de distanciamento social. Com isto, os autores/as destacam o desafio e os reflexos impostos por essas modalidades de ensino, no que concerne centralmente à ausência de um espaço especificamente educativo de interação diferente do espaço familiar e às restrição que advêm de um ensino quando transmitido digitalmente. A partir de então os autores avançam a problematização apontando para a necessidade de que sejam promovidos processos organizacionais, nas instituições de ensino, que reconheçam as possibilidades da educação a distância.

Vimos até aqui uma série de abordagens interessantes sobre o problema da pandemia. Nos últimos artigos tivemos a presença de esforços para pensá-la no âmbito das teses do sistemamundo; associá-la ao amplo debate a respeito da conceituação da "crise" da "crítica"; aos inúmeros desafios que ela traz para a educação, especialmente com a modalidade das aulas on line e assim por diante. Nos dois próximos artigos, que fecham o Dossiê, temos ainda mais dois temas, mostrando o quão plural podem ser as abordagens sobre o nosso contexto pandêmico. $\mathrm{O}$ primeiro, escrito por Ana Paula Simonaci, Evelyn Goyannes Dill Orrico e Eliezer Pires da Silva, Discurso de divulgação científica e canal Nerdologia no Youtube, traz a discussão para as redes sociais na internet, apresentando um canal de divulgação científica do Youtube, "Nerdologia", que tem tido um papel muito importante no debate público por conta da presença de um dos seus idealizadores: o biólogo Átila Iamarino. Mas esse papel de divulgação científica, 
inclusive relacionado à vacinação, não vem de agora. $\mathrm{O}$ artigo mostra a importância da presença de meios de comunicação alternativos de divulgação científica, não restritos à comunidade acadêmica, como no caso dos canais de redes sociais digitais, especialmente em tempos de "negacionismo" científico explícito, com a existência de movimentos organizados com o intuito de descredibilizar a pesquisa científica e, mesmo, medidas comuns de proteção biomédica, como a vacinação em massa.

\section{Por fim, Em contexto de pandemia: entregadores de aplicativos, precarização do} trabalho, esgotamento e mobilização, escrito por Julice Salvagni, Renato Koch Colomby e Cibele Cheron, o balanço sobre as consequências da pandemia é feito a partir da condição social dos trabalhadores precarizados, responsáveis pela entrega de produtos através de aplicativos de serviço. Com o fechamento momentâneo de parte expressiva do comércio, as exigências do consenso biomédico pelo isolamento social, houve uma demanda maior por este tipo de serviço. No entanto, como se define propriamente este segmento da classe trabalhadora, que se encontra numa das situações de maior vulnerabilidade no contexto da pandemia? De que modo é possível ver, nas suas reinvindicações por direitos sociais mínimos, no esgotamento sociopsicológico presente nas jornadas sem fim de trabalho, a expressão de um processo amplo de precarização das garantias mínimas de direitos aos trabalhadores das classes populares em tempos de consenso "neoliberal" e "flexibilização" das leis trabalhistas, ainda mais acentuado com o alto risco de contágio e alta letalidade da pandemia da Covid-19? O artigo mobiliza um amplo quadro conceitual, onde se destaca o conceito de "esgotamento" como princípio regulador da análise, e reflexões de autores como Habermas, Safatle, Pelbart, Harvey e Foucault, entre outros.

Enfim, o que podemos ver na pluralidade temática e de abordagem dos artigos do presente Dossiê, é que a sociedade real é complexa, heterogênea, e exige, a nós sociólogos, que prezamos e cultivamos as ciências sociais, sempre precaução metodológica e lealdade aos procedimentos mínimos de análise, tendo em vista a singularidade e complexidade do nosso objeto de estudo. Num contexto pandêmico, de grande dimensões como o nosso, a realidade social fica ainda mais envolta de ambivalências, fantasmagorias e enigmas cuja decifração exige a observação paulatina, a atenção concentrada, o cuidado e mesmo um bem vindo ceticismo metodológico em relação às seduções da moralização do argumento. Se para alguns é tentador aliarmos nossos trabalhos a determinados princípios normativos, considerados consensuais ou hegemônicos no nosso campo, para nós parece mais correto e salutar nos aliarmos ao trabalho da paciência dos conceitos, do uso correto e honesto de dados empíricos, e da abertura para o espanto diante da realidade objetiva, inclusive a social, que pode muitas vezes não coincidir justamente com os princípios normativos hegemônicos e consensuais do nosso campo. 


\section{Referências}

RODRIGUES, Léo; COSTA, Everton; GUEDES, Eduardo (2020), 'Em tempos de pandemia: para um pós-epidêmico como oportunidade virtuosa”. Simbiótica. Edição Especial, v. 7, n. 1, pp. 1-10.

The Matrix (1999). Direção: Lilly Wachows; Lana Wachowsk. Produção: Joel Silver. Estados Unidos, Warner Bros. Cinema. 